\title{
Titanium Doping of the Metallic One-Dimensional Antiferromagnet, $\mathrm{Nb}_{12} \mathrm{O}_{29}$
}

\author{
Izabella Kruk ${ }^{1}{ }^{1}$, Joanna E. L. Waldron ${ }^{1}$ and Mark A. Green ${ }^{2, *(\mathbb{B}}$ \\ 1 Department of Chemistry, University College London, Christopher Ingold Building, 20 Gordon Street, \\ London WC1H 0AJ, UK; iza.oshaughnessy@gmail.com (I.K.); jo.waldron@mandg.co.uk (J.E.L.W.) \\ 2 School of Physical Sciences, Ingram Building, University of Kent, Canterbury, Kent CT2 7NH, UK \\ * Correspondence: m.green@kent.ac.uk
}

Received: 4 March 2019; Accepted: 21 May 2019; Published: 23 May 2019

\begin{abstract}
Monoclinic $\mathrm{Nb}_{12} \mathrm{O}_{29}$ undergoes a charge ordering transition to form antiferromagnetic $\mathrm{Nb}^{4+}$ chains $\left(\mathrm{T}_{\mathrm{N}} \sim 12 \mathrm{~K}\right.$ ) spaced $15.7 \AA$ apart, which are coupled through mediation from a subset of metallic electrons which are present over all temperature regimes. We present the effects of disrupting the delicate electronic equilibrium in monoclinic $\mathrm{Nb}_{12} \mathrm{O}_{29}$ through doping $\mathrm{Nb}^{4+}\left(\mathrm{d}^{1}\right)$ with $\mathrm{Ti}^{4+}\left(\mathrm{d}^{0}\right)$ ions in the series, $\mathrm{Ti}_{x} \mathrm{Nb}_{12-} \mathrm{O}_{29}$. Powder neutron diffraction demonstrates that $\mathrm{Ti}$ is distributed over all of the 6 crystallographically distinct $\mathrm{Nb}$ positions. Magnetic susceptibility measurements reveal a rapid suppression of the magnetic ordered state on Ti doping, with a 3\% percolation threshold consistent with the existence of one-dimensional $\mathrm{Nb}^{4+}$ chains. The reduction of the number of unpaired electrons on $\mathrm{Ti}^{4+}$ doping is shown to depopulate both localised and itinerant electron subsets, demonstrating that they are intrinsic to the properties of the system, which is argued to be a direct consequence of the mixture of bonding schemes within the lattice.
\end{abstract}

Keywords: magnetic oxides; antiferromagnetic ordering; niobium oxides; charge ordering

\section{Introduction}

Charge ordering is a property of mixed valent solids, where below a temperature defined as $\mathrm{T}_{\mathrm{CO}}$, different electronic configurations adopt distinct crystallographic arrangements. Charge ordering has become an important issue in understanding the electronic properties of transition metal oxides. Prominent examples include the ordering of $\mathrm{Mn}^{3+}$ and $\mathrm{Mn}^{4+}$ ions in perovskite manganates, creating a localised electronic state that is in competition with the ferromagnetic metallic state associated with colossal magnetoresistance. These competing interactions result in compositions that display a transition between the two states as a function of temperature [1]. The metal-insulator transition in $\mathrm{Fe}_{3} \mathrm{O}_{4}$ lead Verwey to predict the ordering of $\mathrm{Fe}^{2+}$ and $\mathrm{Fe}^{3+}$ ions within the spinel lattice [2], which was the first realisation of this phenomena and the extent to which it can influence the electronic properties of strongly correlated electronic systems. A related property found in many ceramics is that of cation ordering of different atoms within a lattice. For example, $\mathrm{Ba}_{3} \mathrm{ZnTa}_{2} \mathrm{O}_{9}$ contains ordered $\mathrm{Zn}$ and $\mathrm{Ta}$ ions in the perovskite framework [3], the extent of which critically affects the dielectric response in the material. It has been suggested that the gross differences in size and charge are the controlling factors behind the ordering of ions that may otherwise reside on crystallographically-equivalent sites. Charge ordering is the electronic analogue of cation ordering; it is a consequence of electron rather than atomic ordering, and can occur in extremely complex arrangements, which is demonstrated by the charge ordering of $\mathrm{Ir}^{3+/} \mathrm{Ir}^{4+}$ ions in $\mathrm{CuIr}_{2} \mathrm{~S}_{4}$ [4] or the $\mathrm{Mn}^{3+/} \mathrm{Mn}^{4+}$ ions in $\mathrm{LiMn}_{2} \mathrm{O}_{4}$ [5].

Monoclinic $\mathrm{Nb}_{12} \mathrm{O}_{29}$ or $\mathrm{Nb}^{4+}{ }_{2} \mathrm{Nb}^{5+}{ }_{10} \mathrm{O}_{29}$ has novel metallic and low dimensional antiferromagnetic properties, despite its relatively low numbers of unpaired electrons [6-9], similar to its orthorhombic polymorph [10]. Its crystallographic shear plane structure is composed of $(4 \times 3)$ blocks of corner-shared 
$\mathrm{NbO}_{6}$ octahedra, which are edge shared to the next $(4 \times 3)$ block in a diagonal arrangement in the $\mathrm{xz}$ plane, shown in Figure 1.

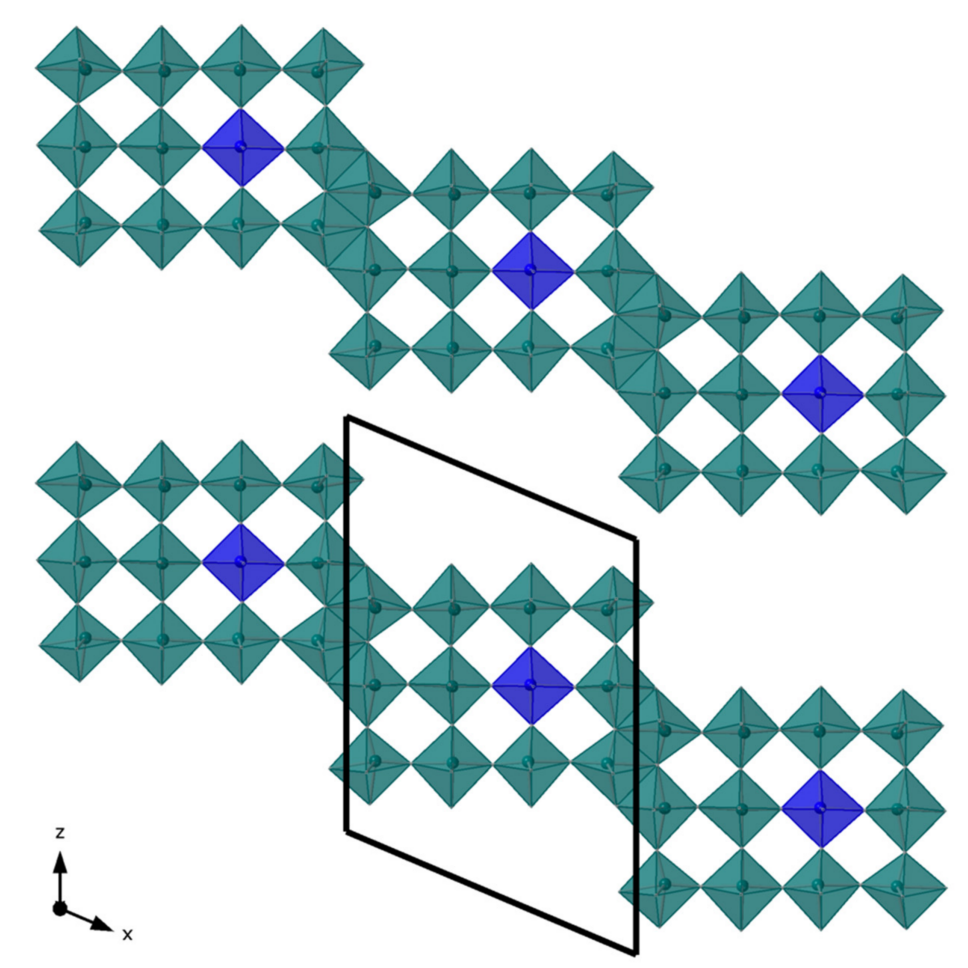

Figure 1. Crystallographic shear structure of monoclinic $\mathrm{Nb}_{12} \mathrm{O}_{29}$, composed of $(4 \times 3)$ blocks of $\mathrm{NbO}_{6}$ octahedral units. Green polyhedral represent $\mathrm{Nb}^{5+}\left(\mathrm{d}^{0}\right)$ octahedral units, where the $\mathrm{Nb}^{4+}\left(\mathrm{d}^{1}\right)$ octahedral units forming chains down the y axis are shown in blue.

The long-ranged, magnetically ordered state is accomplished through a charge ordering transition $[8,11]$. The localisation of $\mathrm{Nb}^{4+}$ ions $\left(\mathrm{d}^{1}, \mathrm{~S}=1 / 2\right)$ occurs on a specific crystallographic site, amidst neighbouring diamagnetic $\mathrm{Nb}^{5+}\left(\mathrm{d}^{0}, \mathrm{~S}=1 / 2\right)$ ions, which repeats down the $y$-axis, giving rise to the formation of chains. The one-dimensional chains of localised $\mathrm{Nb}^{4+}(S=1 / 2)$ order in three dimensions owing to interactions with a subset of delocalised electrons. Zero-field $\mu \mathrm{SR}$ and magnetic susceptibility measurements confirm the presence of a long-range antiferromagnetic state, rather than the more probable spin glass configuration for magnetic impurities embedded in a sea of conduction electrons [11]. $\mathrm{Nb}_{12} \mathrm{O}_{29}$ is an important example of how a low dimensional magnetic structure, with chains of exceptional distances apart $(10.5,15.1$ and $15.7 \AA)$, can be derived from a condensed three-dimensional structure. An interesting comparison can be drawn with the magnetic interactions in $\mathrm{Nb}_{12} \mathrm{O}_{29}$ and those of organic magnets. The reason for this is that for true low dimensional character, the magnetic exchange needs to be very anisotropic (e.g., for $1 D$ systems, $J_{\text {chain }}>>>J_{\text {interchain}}$ ), and therefore, to possess different exchange lengths. Organic magnets can provide suitable separation through the inclusion of bulky organic ligands, which is not possible in dense condensed matter systems. The low temperature structure of monoclinic $\mathrm{Nb}_{12} \mathrm{O}_{29}$, comprises of $\mathrm{Nb}^{4+}(\mathrm{S}=1 / 2)$ chains with distances of at least $10.5 \AA$ apart and represent an important example of the unusual electronic properties that can be achieved when mixed $d^{1}(S=1 / 2)$ and diamagnetic $d^{0}$ ions occupy the same lattice. The susceptibility of the occurrence of reside on different crystallographic sites is provided by the different environment that the two electronic configurations prefer. $\mathrm{Nb}^{4+}\left(\mathrm{d}^{1}\right)$ ions tend to undergo an out-of-centre distortion, providing one short, one long and 4 equal bonds in the octahedral environment, to which $\mathrm{d}^{1}$ ions are less susceptible; therefore, systems can often lower their energy at low temperature by arranging these different configurations onto distinct crystallographic sites. The particular relevance of this in terms of the electronic structure is that ordered systems containing mixed $\mathrm{d}^{0}$ and $\mathrm{d}^{1}$ ions are composed of 
closed and open shell electronic configurations, respectively, and offer the opportunity of producing unique electronic ground states.

Long ranged antiferromagnetic order is not commonly observed concomitantly with metallic properties, as the formation of antiparallel spins normally prohibits free movement of electrons, although there are many cases where there is a subtle balance between antiferromagnetic localised character and metallic itinerant properties. This is particularly pertinent in the electronic properties of high temperature superconducting cuprates, where the destruction of antiferromagnetic order with chemical doping can result in a transition to a superconducting state. Niobium oxides provide an interesting analogy to the high $\mathrm{T}_{\mathrm{C}}$ cuprates, both $\mathrm{NbO}$ [12] and $\mathrm{A}_{x} \mathrm{NbO}_{2}$ [13] undergo superconducting transitions. It might be expected that $\mathrm{Nb}_{12} \mathrm{O}_{29}$ show such a transition through similar strong metal-metal bonding, though the formation of localised magnetic electrons alongside metallic electrons may tend to suppress the superconducting state. Therefore, investigations of doped $\mathrm{Nb}_{12} \mathrm{O}_{29}$ are important in the study of the limit of the antiferromagnetic state, and to investigate whether suppression of the long ranged magnetic state results in superconductivity, as observed in certain cuprates. Furthermore, it is interesting to note the symmetric nature of the electronic configuration between these niobates and high $\mathrm{T}_{\mathrm{C}}$ cuprates, with $\mathrm{Nb}^{4+}$ possessing $\mathrm{d}^{1}(\mathrm{~S}=1 / 2)$ and the high temperature superconducting cuprates based on doped $\mathrm{d}^{9}(\mathrm{~S}=1 / 2)$ systems.

The origin of the magnetism in $\mathrm{Nb}_{12} \mathrm{O}_{29}$ has been extensively discussed. First principal calculations have suggested a Stoner instability attributed to $\mathrm{Nb}$ ions close to a valence of 5+ [14], whereas a more recently study has found the presence of low dimensional spin chains [15]. In this paper, we show that doping of very small amounts of $\mathrm{Nb}^{4+}\left(\mathrm{d}^{1}\right)$ with diamagnetic $\mathrm{Ti}^{4+}\left(\mathrm{d}^{0}\right)$ ions in $\mathrm{Nb}_{12} \mathrm{O}_{29}$ destroys the long-range magnetic order, revealing a low percolation threshold of around $3 \%$, consistent with the presence of one-dimensional antiferromagnetic magnetic ordering. Both the metallic conduction and balance between localised and itinerant electrons remains with low concentrations of Ti, providing strong evidence that the electrons involved in the one-dimensional antiferromagnetic ordering and metallic properties originate from distinct electronic subsets.

\section{Results and Discussion}

Compositions with the formulae $\mathrm{TiNb}_{11} \mathrm{O}_{29}$ and $\mathrm{Ti}_{2} \mathrm{Nb}_{10} \mathrm{O}_{29}$ have both been previously reported [16-18], making the formation of a $\mathrm{Ti}_{x} \mathrm{Nb}_{12-x} \mathrm{O}_{29}(0 \leq x \leq 2)$ solid solution likely. The $\mathrm{Ti}_{x} \mathrm{Nb}_{12-x} \mathrm{O}_{29}$ series formed single phase materials with the monoclinic $\mathrm{Nb}_{12} \mathrm{O}_{29}$ structure throughout the range $0<x<1$, although requiring different synthesis conditions. The volume of the resulting unit cell, shown in Figure 2a, was found to vary smoothly with composition, confirming homogeneous inclusion of the different sized Ti ions into the lattice. SQUID magnetometry measurements showed an equally consistent reduction in the Curie constant, $\mathrm{C}$ and Weiss Temperature, $\theta$, as obtained from the fitting of the magnetic susceptibility to the Curie-Weiss relationship in the paramagnetic regime, further demonstrating the homogeneous inclusion of Ti as well as its direct effect on the amount of localised moment, as shown in Figure 2b,c.

Powder neutron diffraction was collected on one composition, $\mathrm{TiNb}_{11} \mathrm{O}_{29}$, at room temperature to give an estimation of the distribution of the $\mathrm{Ti}$ and $\mathrm{Nb}$ atoms within the lattice. Powder $\mathrm{X}$-ray diffraction data was well fitted in the A 2/m space group, as determined for monoclinic $\mathrm{Nb}_{12} \mathrm{O}_{29}$ at room temperature [8], which was confirmed with neutron diffraction and shown in Figure 3. Rietveld refinement of the neutron powder diffraction pattern of the $\mathrm{Ti}_{x} \mathrm{Nb}_{12-x} \mathrm{O}_{29}$ series is particularly accurate in determining the composition of the 6 crystallographic inequivalent metal sites, due to the contrasting coherent neutron scattering lengths of $-3.438 \mathrm{fm}(\mathrm{Ti})$ and $7.054 \mathrm{fm}(\mathrm{Nb})$. A previous neutron study of $\mathrm{Ti}_{2} \mathrm{Nb}_{12} \mathrm{O}_{29}$ has shown the Ti atoms to show a slight preference to be located on the edges of the $(4 \times 3)$ block [18]. In contrast, the fractional occupancies in these refinements showed the Ti and $\mathrm{Nb}$ in $\mathrm{TiNb}_{11} \mathrm{O}_{29}$ to be evenly distributed over all site. The resulting atomic coordinates are provided in Table 1. The difference in the results from the two neutron patterns can be accounted for by the very different synthetic techniques used. The synthesis of $\mathrm{Ti}_{2} \mathrm{Nb}_{10} \mathrm{O}_{29}$, containing only d $\mathrm{d}^{0}$ ions, was 
reported to be formed in normal atmospheric conditions over long synthesis periods, thereby achieving the thermodynamically most stable product [18].Through Rietveld refinement of a large spectrum of samples formed under different synthetic conditions, we have demonstrated that the most crystalline samples are produced through a rapid synthesis procedure at extremely hot temperature [7]. A typical route for Ti containing $\mathrm{Nb}_{12} \mathrm{O}_{29}$ would involve temperatures of $1280^{\circ} \mathrm{C}$ for $75 \mathrm{~min}$, followed by rapid quenching, which would tend to produce a kinetically stable product and does not allow the Ti and $\mathrm{Nb}$ to order in the most energetically favourable manner. From these arguments, and as all samples are produced under similar synthetic conditions, other compositions are assumed to have the same even distribution of Ti ions.
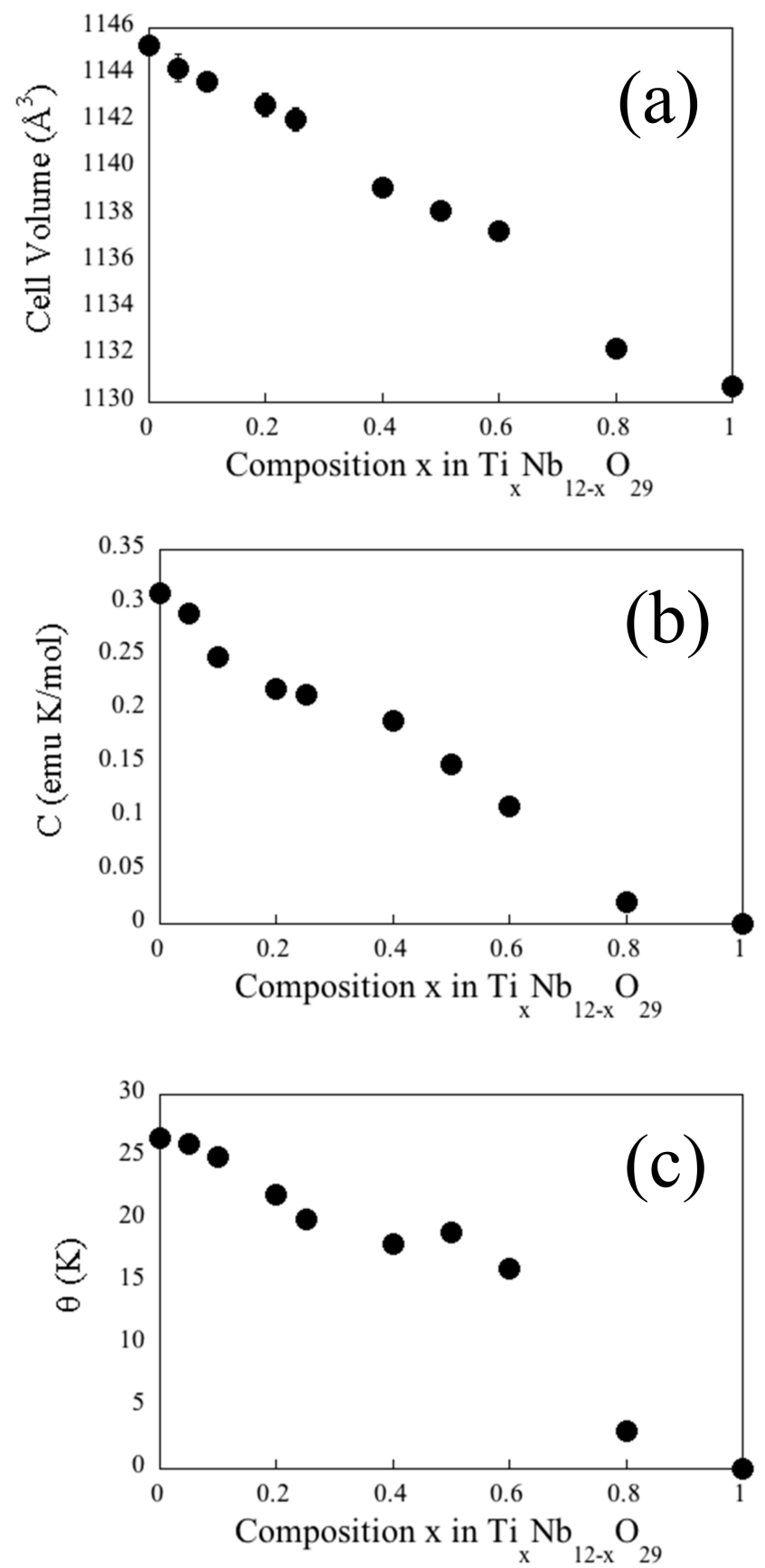

Figure 2. The variation of the (a) volume of unit cell (b) Curie constant, $C$ and (c) Weiss temperature, $\theta$, as a function of $\mathrm{Ti}$ doping in $\mathrm{Ti}_{x} \mathrm{Nb}_{12-x} \mathrm{O}_{29}$, demonstrating the homogeneous inclusion of the Ti ions into the $\mathrm{Nb}_{12} \mathrm{O}_{29}$ lattice. 


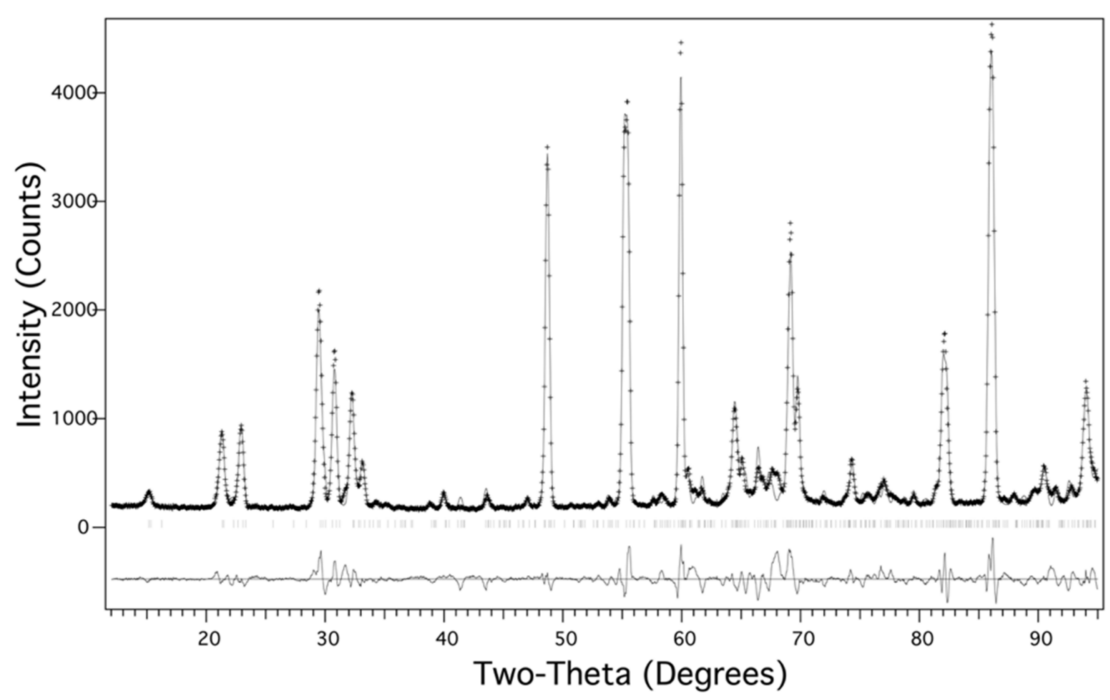

Figure 3. Rietveld refinement of powder neutron diffraction data of $\mathrm{TiNb}_{11} \mathrm{O}_{29}$ at room temperature.

Table 1. Atomic position and site occupancy of $\mathrm{TiNb}_{11} \mathrm{O}_{29}$ at room temperature, as determined from Rietveld refinement of powder neuron diffraction data in the monoclinic A 2/m space group.

\begin{tabular}{cccc}
\hline & $\mathbf{x}$ & $\mathbf{y}$ & $\mathbf{z}$ \\
\hline $\mathrm{Nb} / \mathrm{Ti}(1)$ & $0.0973(15)$ & 0 & $0.0760(14)$ \\
$\mathrm{Nb} / \mathrm{Ti}(2)$ & $0.0906(18)$ & 0 & $0.6839(17)$ \\
$\mathrm{Nb} / \mathrm{Ti}(3)$ & $0.1098(13)$ & 0 & $0.8781(12)$ \\
$\mathrm{Nb} / \mathrm{Ti}(4)$ & $0.3749(12)$ & 0 & $0.1507(10)$ \\
$\mathrm{Nb} / \mathrm{Ti}(5)$ & $0.3598(14)$ & 0 & $0.7633(15)$ \\
$\mathrm{Nb} / \mathrm{Ti}(6)$ & $0.3502(17)$ & 0 & $0.9554(15)$ \\
$\mathrm{O}(13)$ & $1 / 2$ & 0 & 0 \\
$\mathrm{O}(14)$ & $0.0660(17)$ & 0 & $0.1740(16)$ \\
$\mathrm{O}(15)$ & $0.0659(19)$ & 0 & $0.3545(14)$ \\
$\mathrm{O}(16)$ & $0.0752(15)$ & 0 & $0.5872(14)$ \\
$\mathrm{O}(17)$ & $0.0669(14)$ & 0 & $0.7711(14)$ \\
$\mathrm{O}(18)$ & $0.0842(14)$ & 0 & $0.9735(12)$ \\
$\mathrm{O}(19)$ & $0.2187(14)$ & 0 & $0.0974(14)$ \\
$\mathrm{O}(20)$ & $0.2315(16)$ & 0 & $0.7312(15)$ \\
$\mathrm{O}(21)$ & $0.2155(16)$ & 0 & $0.9206(14)$ \\
$\mathrm{O}(22)$ & $0.3706(14)$ & 0 & $0.0579(14)$ \\
$\mathrm{O}(23)$ & $0.3559(17)$ & 0 & $0.2515(15)$ \\
$\mathrm{O}(24)$ & $0.3554(17)$ & 0 & $0.4445(13)$ \\
$\mathrm{O}(25)$ & $0.3609(16)$ & 0 & $0.6696(17)$ \\
$\mathrm{O}(26)$ & $0.3619(15)$ & 0 & $0.8555(14)$ \\
$\mathrm{O}(27)$ & $0.4919(16)$ & 0 & $0.1863(14)$ \\
\hline
\end{tabular}

Figure 4 shows the magnetic susceptibility of three members of the $\mathrm{Ti}_{x} \mathrm{Nb}_{12-x} \mathrm{O}_{29}$ series below $25 \mathrm{~K}$. It demonstrates that the temperature of the magnetic transition, as determined from the point of steepest gradient below the maximum, is extremely sensitive to composition. The Neel temperature of approximately $12 \mathrm{~K}$ for $\mathrm{Nb}_{12} \mathrm{O}_{29}$ is shifted down to around $8.5 \mathrm{~K}$ for $\mathrm{Ti}_{0.05} \mathrm{Nb}_{11.95} \mathrm{O}_{29}$. An increase in the Ti concentration to $\mathrm{Ti}_{0.1} \mathrm{Nb}_{11.9} \mathrm{O}_{29}$ further reduces the ordering temperature to around $6.5 \mathrm{~K}$. At low temperatures, $\mathrm{Ti}_{0.1} \mathrm{Nb}_{11.9} \mathrm{O}_{29}$ and compositions with Ti content greater than 0.1 show an additional increase in the susceptibility below the ordering temperature. The appearance of this Curie-tail is characteristic of doped low dimensional magnetic systems. The inclusion of the non-magnetic $\mathrm{Ti}^{4+}$ impurities, although amounting to less than $1 \%$ of the metal content in the lattice, fragments the alignment of $\mathrm{Nb}^{4+}$ spins and hinders the formation of a long range ordered state. Compositions with $x>0.3$ show purely Curie-Weiss behaviour over the entire temperature range, and no transition to a 
long ranged ordered state is seen. A summary of the antiferromagnetic ordering temperatures across the series is given in Figure 5a, showing the consistent suppression of ordering temperature with Ti doping. These measurements are limited to temperature of $1.8 \mathrm{~K}$ and above; however, it is clear from extrapolation of $\mathrm{T}_{\mathrm{N}}$ across the series that the loss of long range magnetic order occurs at $x \sim 0.35$, corresponding to around $3 \%$ doping level.
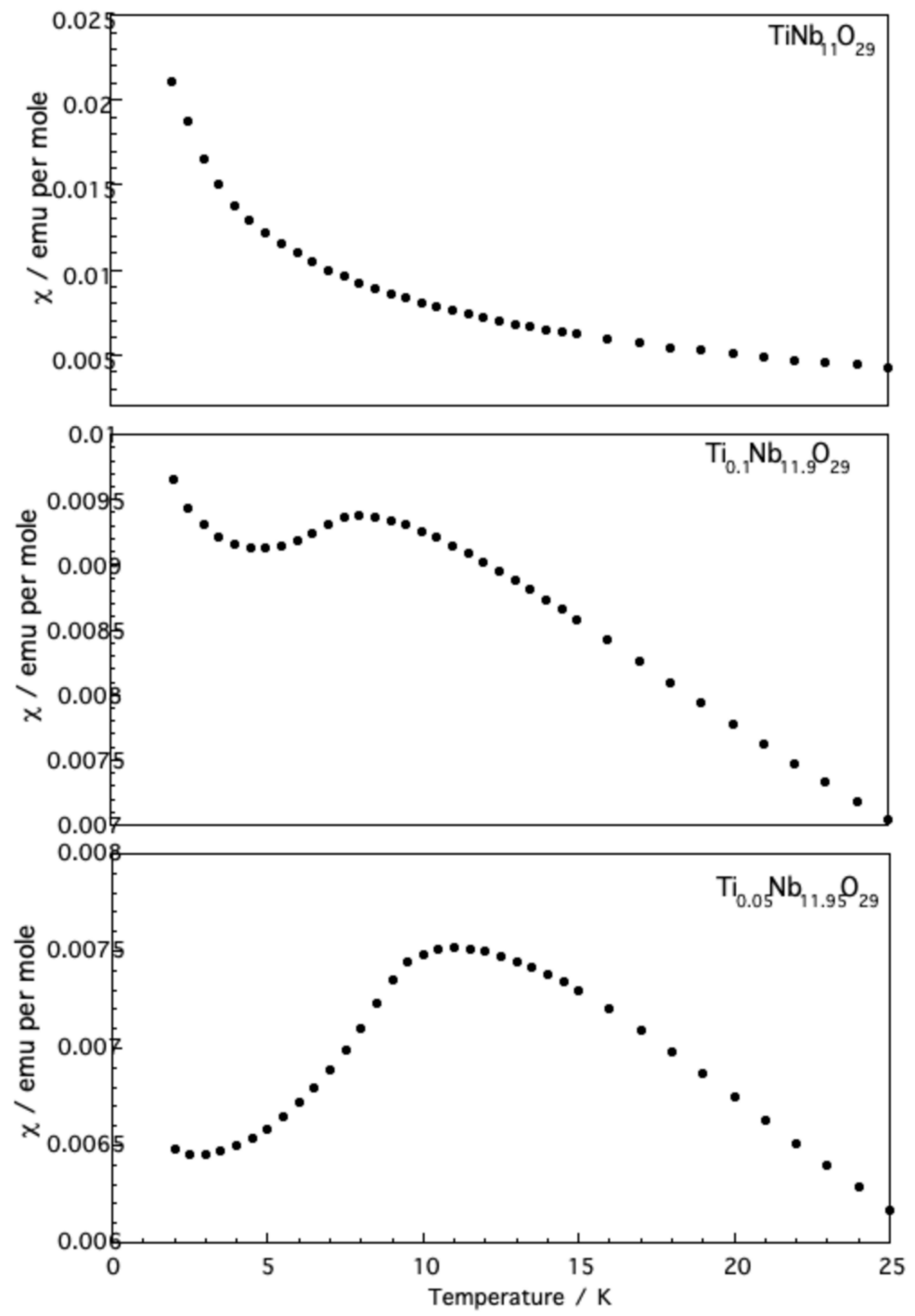

Figure 4. Magnetic Susceptibility from 2-25 $\mathrm{K}$ of $\mathrm{Ti}_{0.05} \mathrm{Nb}_{11.95} \mathrm{O}_{29}, \mathrm{Ti}_{0.1} \mathrm{Nb}_{11.9} \mathrm{O}_{29}$ and $\mathrm{TiNb}_{11} \mathrm{O}_{29}$, showing a rapid suppression of the antiferromagnetic ordering, as well as an increase in the Curie tail, on increasing Ti concentration.

The amount of non-magnetic dopant required to destroy long range magnetic ordering is crucially dependent on the dimensionality of the magnetic structure. Three-dimensional systems, where the exchange energy is approximately equal in all three spatial dimensions, are relatively resilient to non-magnetic impurities. Two-dimensional, long-range magnetic systems, where the exchange energy is greater within planes than in the third direction, is destroyed at lower concentrations than in the three-dimensional case. One-dimensional magnetic systems, where the exchange energy along one direction, forming chains, is greater than in the other two, can only tolerate very small changes in the stoichiometry. The destruction of magnetic order with dopant ions is related to the percolation threshold, which changes with dimensionality and structure. A two-dimensional square lattice has a percolation threshold of 0.5 , whereas the theoretically percolation threshold for a one-dimensional 
magnet is 1 , that is, there is no tolerance for non-magnetic impurities. There are a number of example of this in the literature, the one-dimensional spin-Peierls transition in $\mathrm{CuGeO}_{3}$ can be destroyed by doping of only $2 \% \mathrm{Zn}$ on the copper site [19]. Similarly the transition in $\mathrm{Na}_{x} \mathrm{~V}_{2} \mathrm{O}_{5}$ to a low dimensional zigzag arrangement [20] is destroyed when $x \leq 0.97$, which effectively introduces $3 \%$ of non-magnetic $\mathrm{V}^{5+}$ into the $\mathrm{V}^{4+}$ chains [21]. The low percolation threshold for Ti doped $\mathrm{Nb}_{12} \mathrm{O}_{29}$ (around 3\%), is consistent with the one-dimensional nature of the magnetic structure.

Figure $5 \mathrm{~b}$ shows the temperature dependence of the resistivity of $\mathrm{Ti}_{x} \mathrm{Nb}_{12-x} \mathrm{O}_{29}(x=0.0,0.05,0.1$ and 0.2). As these experiments were performed on powdered samples, the effect of grain boundaries can vary from one experiment to another, thereby undermining the reliable of the absolute values. However, all the samples show metallic behaviour and exhibit a general trend for the resistivity to reduce with the amount of Ti doping. This result may initially seem somewhat counterintuitive, as substitution of $\mathrm{Nb}^{4+}$ with $\mathrm{Ti}^{4+}$ reduces the number of unpaired electrons in the system and the presence of defects reduces the $\mathrm{Nb}-\mathrm{O}$ and $\mathrm{Nb}-\mathrm{Nb}$ overlap; however, the basis for this may lie in the interaction between the localised and itinerant electrons. The increase in the concentration of $\mathrm{Ti}^{4+}$ ions also reduces the number of localised electrons and, therefore, the scattering between the itinerant and localised electrons, whilst the depopulation of the conduction band and lowering of the Fermi energy may not necessarily have a significant effect at such low values of $x$.
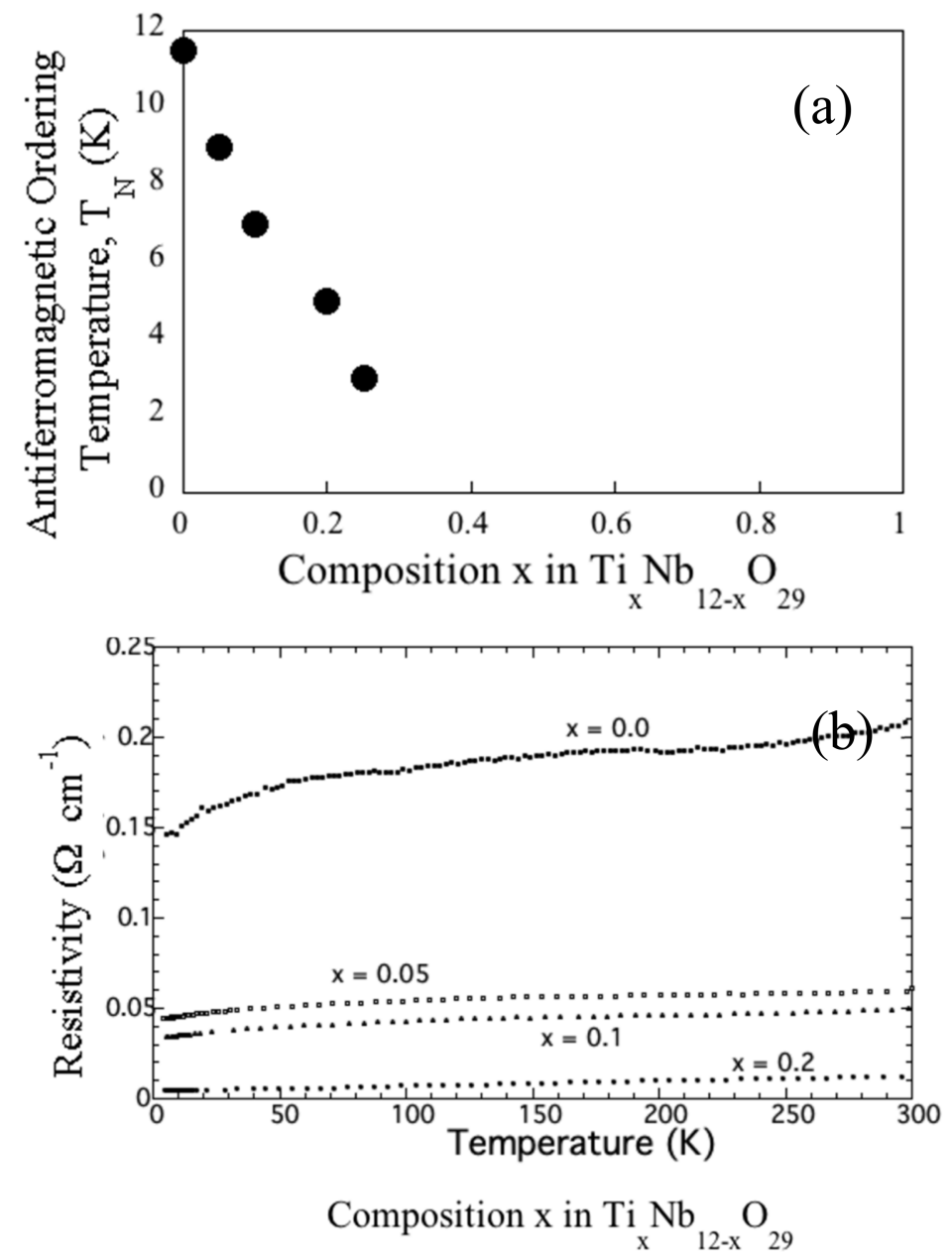

Figure 5. The (a) antiferromagnetic ordering temperatures and (b) resistivity of selected members of the $\mathrm{Ti}_{x} \mathrm{Nb}_{12-x} \mathrm{O}_{29}$ series showing the rapid suppression of long ranged magnetic behaviour with Ti doping.

The origin of the localised and itinerant electrons is an important issue in the electronic properties of these materials, which is governed by the complex bonding scheme in the monoclinic block structure. 
The retention of the balance between localised and delocalised electrons is in stark contrast to the properties of many charge-ordered systems such as $\mathrm{Fe}_{3} \mathrm{O}_{4}$ or the manganate perovskites. Here, the localised and delocalised properties are in direct competition and the charge ordering causes all of the electrons to localise that were previously itinerant, thereby causing a metal-insulator transition. In the case of $\mathrm{Ti}_{x} \mathrm{Nb}_{12-x} \mathrm{O}_{29}$, the electrons can be thought of as distinct subsets of electrons that are intrinsic to the structure. A unit cell of the $(\mathrm{Ti}, \mathrm{Nb})-\mathrm{O}$ structure is shown in Figure 6. It contains corner-sharing octahedra where the $\mathrm{Nb}-\mathrm{Nb}$ bond lengths are around $3.7 \AA$ and separated by an oxygen atom, with an $\mathrm{Nb}-\mathrm{O}-\mathrm{Nb}$ bond angle of around $180^{\circ}$. In contrast, the edge- shared octahedra contain $\mathrm{Nb}-\mathrm{O}-\mathrm{Nb}$ bond angles of approximately $90^{\circ}$, producing $\mathrm{Nb}-\mathrm{Nb}$ bond lengths of around $3.18 \AA$. These two bonding schemes will clearly cause differing degrees of $\mathrm{Nb}-\mathrm{Nb}$ and $\mathrm{Nb}-\mathrm{O}$ overlap within the lattice. The octahedra in the centre of the $(4 \times 3)$ block contains only corner-sharing configurations, thereby leading to limited overlap and explaining the localised nature of the $\mathrm{Nb}^{4+}$ ions located at this site. In contrast, the relatively short $\mathrm{Nb}-\mathrm{Nb}$ distances in the outer octahedra of the $(4 \times 3)$ block can give rise to direct $\mathrm{Nb}-\mathrm{Nb}$ overlap, forming a conduction band and resulting in the presence of itinerant electrons. The inclusion of Ti ions in the lattice equally reduces the concentration of both the localised and delocalised electrons, as the underlying combination of edge and corner shared octahedra remains the same.

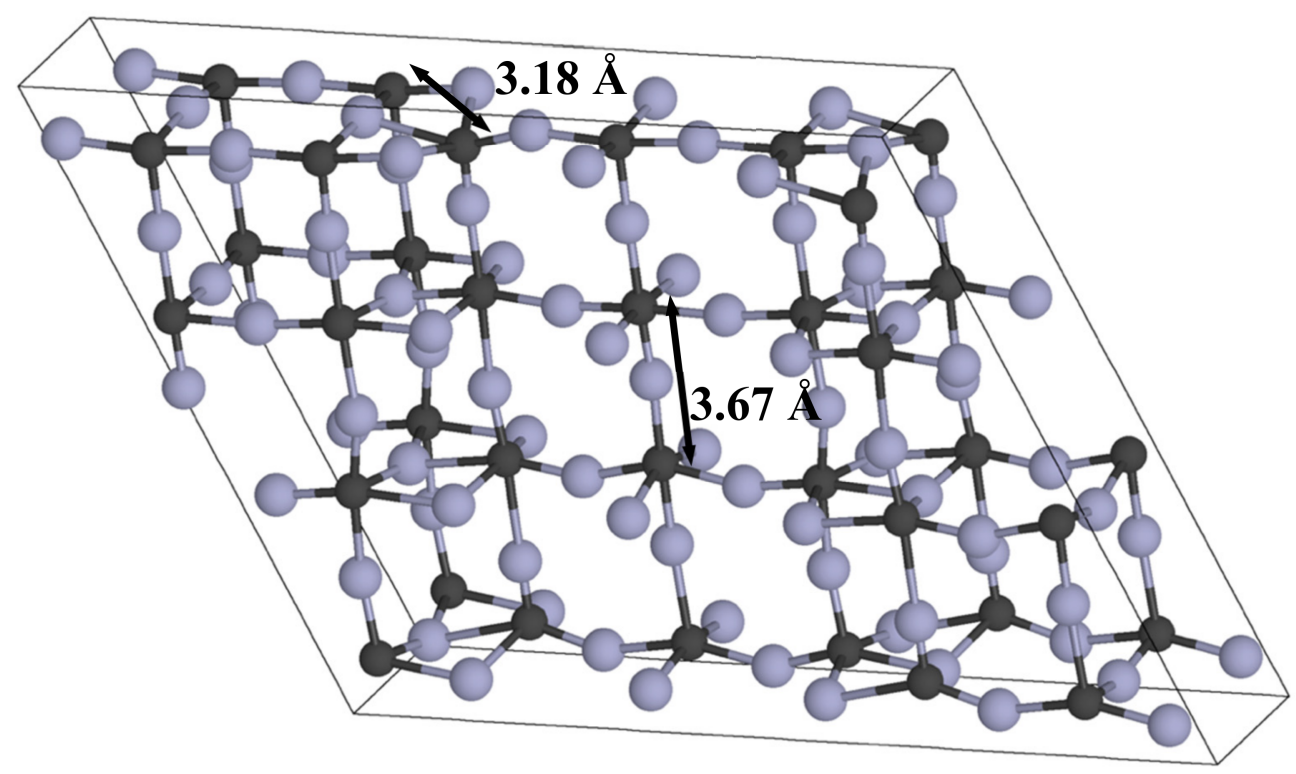

Figure 6. Unit cell of monoclinic, $\mathrm{Nb}_{12} \mathrm{O}_{29}$, showing contrasting bonding of niobium sites on the edge of the $(4 \times 3)$ block, which possess strong metal-metal bonding at distances of $\sim 3.2 \AA$, whereas those in the middle are absent of direct $\mathrm{Nb}-\mathrm{Nb}$ interactions.

\section{Materials and Methods}

Compositions of $\mathrm{Ti}_{x} \mathrm{Nb}_{12-x} \mathrm{O}_{29}(x=0.0,0.05,0.1,0.2,0.25,0.4,0.5,0.6,0.8$ and 1.0) were synthesised from stoichiometric amounts of $\mathrm{Nb}, \mathrm{H}-\mathrm{Nb}_{2} \mathrm{O}_{5}$ and $\mathrm{TiO}_{2} \cdot \mathrm{TiO}_{2}$ was dried before use at $700{ }^{\circ} \mathrm{C}$ for $24 \mathrm{~h}$. Commercially available $\mathrm{Nb}_{2} \mathrm{O}_{5}$ was heated at $1100{ }^{\circ} \mathrm{C}$ for $12 \mathrm{~h}$ before use to convert it to $\mathrm{H}-\mathrm{Nb}_{2} \mathrm{O}_{5}$. The starting materials were thoroughly ground together, made into pellets, and sealed in an evacuated quartz tube. The heating temperatures and times were found to be critical in the synthesis of single-phase materials, which was further sensitive to composition. Samples were heated to high temperature, as described in Table 2, and then removed from the furnace and dropped into cold water to quench the reaction. The phase purity of various products under different synthetic conditions was determined by Rietveld refinement of powder X-ray diffraction, obtained from a Siemens D500 diffractometer (Siemens now Bruker, Karlsruhe, Germany). The optimal synthetic conditions for different Ti compositions are summarised in Table 2, and a typical X-ray pattern is shown in Figure 7, 
to demonstrate the high crystallinity achieved with this method. The resulting lattice parameters determined from Rietveld refinement of powder X-ray diffraction data is provided in Table 3. Magnetic susceptibility measurements were performed using a Quantum Design MPMS 7 SQUID magnetometer (Quantum Design, San Diego, CA, USA). Resistivity measurements were performed in the standard four probe technique. Powder neutron diffraction was performed on the D2B diffractometer built at the Institut Laue Langevin, France at a wavelength, $\lambda=1.594 \AA$.

Table 2. Heating conditions for optimal synthesis of the $\mathrm{Ti}_{x} \mathrm{Nb}_{12-x} \mathrm{O}_{29}$ series.

\begin{tabular}{ccc}
\hline Product & Temperature/ ${ }^{\circ} \mathrm{C}$ & Heating Time/min \\
\hline $\mathrm{Nb}_{12} \mathrm{O}_{29}$ & 1280 & 75 \\
$\mathrm{Ti}_{0.05} \mathrm{Nb}_{11.95} \mathrm{O}_{29}$ & 1250 & 75 \\
$\mathrm{Ti}_{0.1} \mathrm{Nb}_{11.9} \mathrm{O}_{29}$ & 1250 & 75 \\
$\mathrm{Ti}_{0.2} \mathrm{Nb}_{11.8} \mathrm{O}_{29}$ & 1250 & 60 \\
$\mathrm{Ti}_{0.25} \mathrm{Nb}_{11.75} \mathrm{O}_{29}$ & 1250 & 60 \\
$\mathrm{Ti}_{0.4} \mathrm{Nb}_{11.6} \mathrm{O}_{29}$ & 1250 & 50 \\
$\mathrm{Ti}_{0.5} \mathrm{Nb}_{11.5} \mathrm{O}_{29}$ & 1250 & 50 \\
$\mathrm{Ti}_{0.6} \mathrm{Nb}_{11.4} \mathrm{O}_{29}$ & 1250 & 45 \\
$\mathrm{Ti}_{0.8} \mathrm{Nb}_{11.2} \mathrm{O}_{29}$ & 1250 & 45 \\
$\mathrm{TiNb}_{11} \mathrm{O}_{29}$ & 1250 & 40 \\
\hline
\end{tabular}

Table 3. Unit cell parameters of the $\mathrm{Ti}_{x} \mathrm{Nb}_{12-x} \mathrm{O}_{29}$ series as determined from $\mathrm{X}$-ray powder diffraction.

\begin{tabular}{cccccc}
\hline Sample & $\mathbf{a}(\AA)$ & $\mathbf{b}(\AA)$ & $\mathbf{c}(\AA)$ & $\beta\left(^{\circ}\right)$ & Volume $\left(\AA^{\mathbf{3}}\right)$ \\
\hline $\mathrm{Nb}_{12} \mathrm{O}_{29}$ & $15.6920(7)$ & $3.8303(2)$ & $20.7171(9)$ & $113.112(3)$ & $1145.26(2)$ \\
$\mathrm{Ti}_{0.05} \mathrm{Nb}_{11.95} \mathrm{O}_{29}$ & $15.685(4)$ & $3.8306(8)$ & $20.706(4)$ & $113.10(1)$ & $1144.3(6)$ \\
$\mathrm{Ti}_{0.1} \mathrm{Nb}_{11.9} \mathrm{O}_{29}$ & $15.682(3)$ & $3.8297(3)$ & $20.702(3)$ & $113.09(2)$ & $1143.7(4)$ \\
$\mathrm{Ti}_{0.2} \mathrm{Nb}_{11.8} \mathrm{O}_{29}$ & $15.673(3)$ & $3.8278(7)$ & $20.703(4)$ & $113.08(1)$ & $1142.7(5)$ \\
$\mathrm{Ti}_{0.25} \mathrm{Nb}_{11.75} \mathrm{O}_{29}$ & $15.673(3)$ & $3.8286(7)$ & $20.692(4)$ & $113.10(1)$ & $1142.1(5)$ \\
$\mathrm{Ti}_{0.4} \mathrm{Nb}_{11.6} \mathrm{O}_{29}$ & $15.6516(3)$ & $3.8279(1)$ & $20.6699(4)$ & $113.088(14)$ & $1139.18(4)$ \\
$\mathrm{Ti}_{0.5} \mathrm{Nb}_{11.5} \mathrm{O}_{29}$ & $15.6431(2)$ & $3.8277(1)$ & $20.6606(2)$ & $113.059(7)$ & $1138.19(2)$ \\
$\mathrm{Ti}_{0.6} \mathrm{Nb}_{11.4} \mathrm{O}_{29}$ & $15.6351(2)$ & $3.8280(1)$ & $20.6529(2)$ & $113.056(8)$ & $1137.3(2)$ \\
$\mathrm{Ti}_{0.8} \mathrm{Nb}_{11.2} \mathrm{O}_{29}$ & $15.6004(2)$ & $3.8253(4)$ & $20.6191(3)$ & $113.039(9)$ & $1132.29(2)$ \\
$\mathrm{TiNb}_{11} \mathrm{O}_{29}$ & $15.593(3)$ & $3.8221(6)$ & $20.612(4)$ & $113.01(1)$ & $1130.7(5)$ \\
\hline
\end{tabular}

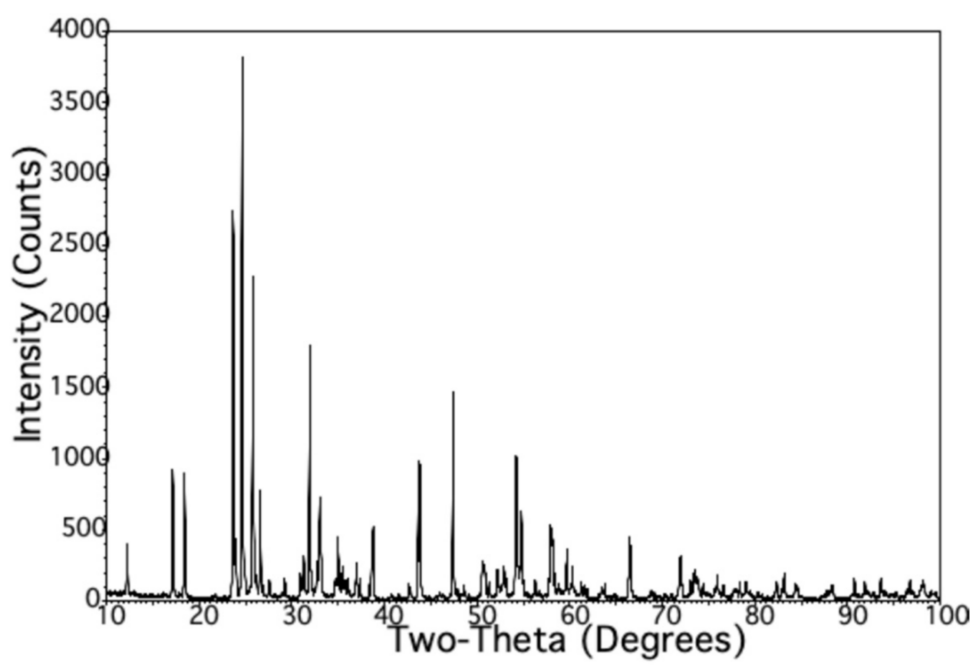

Figure 7. X-ray powder diffraction of $\mathrm{TiNb}_{11} \mathrm{O}_{29}$, demonstrating the highly crystalline oxides formed through a rapid high temperature reaction. 


\section{Conclusions}

The synthesis and characterization of a series of magnetic oxides with the general formula $\mathrm{Ti}_{x} \mathrm{Nb}_{12-x} \mathrm{O}_{29}$ support the hypothesis that this is a low-dimensional magnet created by the localisation of $\mathrm{Nb}^{4+}$ onto specific sites that are absent of metal-metal bonding. These results will greatly help with the understanding of recent electrochemical studies [22].

Author Contributions: I.K., J.E.L.W. and M.A.G. contributed equally to the synthesis and characterization. M.A.G. designed the experiment and wrote the paper.

Funding: This research was funded by the Royal Society (WM120049).

Acknowledgments: We thank the Institute Laue Langevin, France for provision of neutron beam time. We thank Alan Hewat for assistance with the experiments. We thank Manisha Patel with assistance with synthesis and Pawel Zajdel for useful discussions.

Conflicts of Interest: The authors declare no conflict of interest.

\section{References}

1. Rao, C.N.R.; Arulraj, A.; Santosh, P.N.; Cheetham, A.K. Charge-Ordering in Manganates. Chem. Mater. 1998, 10, 2714-2722. [CrossRef]

2. Verwey, E.J.W. Electronic Conduction of Magnetite $\left(\mathrm{Fe}_{3} \mathrm{O}_{4}\right)$ and its Transition Point at Low Temperatures. Nature 1939, 144, 327-328. [CrossRef]

3. Jacobson, A.J.; Collins, B.M.; Fender, B.E.F. A powder neutron and X-ray diffraction determination of the structure of $\mathrm{Ba}_{3} \mathrm{Ta}_{2} \mathrm{ZnO} 9$ : An investigation of perovskite phases in the system $\mathrm{Ba}-\mathrm{Ta}-\mathrm{Zn}-\mathrm{O}$ and the preparation of $\mathrm{Ba}_{2} \mathrm{TaCdO}_{5.5}$ and $\mathrm{Ba}_{2} \mathrm{CeInO}_{5.5}$. Acta Crystallogr. B 1976, 32, 1083-1087. [CrossRef]

4. Radaelli, P.G.; Horibe, Y.; Gutmann, M.J.; Ishibashi, H.; Chen, C.H.; Ibberson, R.M.; Koyama, Y.; Hor, Y.S.; Kiryukhin, V.; Cheong, S.W. Formation of isomorphic $\mathrm{Ir}^{3+}$ and $\mathrm{Ir}^{4+}$ octamers and spin dimerization in the spinel $\mathrm{CuIr}_{2} \mathrm{~S}_{4}$. Nature 2002, 416, 155-158. [CrossRef] [PubMed]

5. Rodríguez-Carvajal, J.; Rousse, G.; Masquelier, C.; Hervieu, M. Electronic Crystallization in a Lithium Battery Material: Columnar Ordering of Electrons and Holes in the Spinel $\mathrm{LiMn}_{2} \mathrm{O}_{4}$. Phys. Rev. Lett. 1998, 81, 4660-4663. [CrossRef]

6. Norin, R.; Hope, H.; Nevald, R.; Frank, V.; Brunvoll, J.; Bunnenberg, E.; Djerassi, C.; Records, R. The Crystal Structure of $\mathrm{Nb}_{12} \mathrm{O}_{29}$ (mon). Acta Chem. Scand. 1966, 20, 871-880. [CrossRef]

7. Waldron, J.E.L.; Green, M.A.; Neumann, D.A. Solid State Symposium, Materials Research Society. In Solid State Symposium, Materials Research Society; Greedan, J.E., Ed.; MRS: Boston, MA, USA, 2000.

8. Waldron, J.E.L.; Green, M.A.; Neumann, D.A. Charge and spin ordering in monoclinic $\mathrm{Nb}_{12} \mathrm{O}_{29}$. J. Am. Chem. Soc. 2001, 123, 5833-5834. [CrossRef]

9. Waldron, J.E.L.; Green, M.A.; Neumann, D.A. Structure and electronic properties of monoclinic $\mathrm{Nb}_{12} \mathrm{O}_{29}$. J. Phys. Chem. Solids 2004, 65, 79-86. [CrossRef]

10. Cava, R.J.; Batlogg, B.; Krajewski, J.J.; Gammel, P.; Poulsen, H.F.; Peck, W.F.; Rupp, L.W. Antiferromagnetism and Metallic Conductivity in $\mathrm{Nb}_{12} \mathrm{O}_{29}$. Nature 1991, 350, 598-600. [CrossRef]

11. Lappas, A.; Waldron, J.E.L.; Green, M.A.; Prassides, K. Magnetic ordering in the charge-ordered $\mathrm{Nb}_{12} \mathrm{O}_{29}$. Phys. Rev. B 2002, 65, 134405. [CrossRef]

12. Hulm, J.K.; Jones, C.K.; Hein, R.A.; Gibson, J.W. Superconductivity in the TiO and NbO Systems. J. Low Temp. Phys. 1972, 7, 291-307. [CrossRef]

13. Geselbracht, M.J.; Richardson, T.J.; Stacy, A.M. Superconductivity in the Layered Compound $\mathrm{Li}_{x} \mathrm{NbO}_{2}$. Nature 1990, 345, 324-326. [CrossRef]

14. Fang, C.M.; Van Huis, M.A.; Xu, Q.; Cava, R.J.; Zandbergen, H.W. Unexpected origin of magnetism in monoclinic $\mathrm{Nb}_{12} \mathrm{O}_{29}$ from first-principles calculations. J. Mater. Chem. C 2015, 3, 651-657. [CrossRef]

15. Lee, K.W.; Pickett, W.E. Organometalliclike localization of 4d-derived spins in an inorganic conducting niobium suboxide. Phys. Rev. B 2015, 91. [CrossRef]

16. Wadsley, A.D. Mixed oxides of titanium and niobium. I. Acta Crystallogr. 1961, 14, 660-664. [CrossRef]

17. Wadsley, A.D. Mixed oxides of titanium and niobium. II. The crystal structures of the dimorphic forms $\mathrm{Ti}_{2} \mathrm{Nb}_{10} \mathrm{O}_{29}$. Acta Crystallogr. 1961, 14, 664-670. [CrossRef] 
18. Dreele, R.B.V.; Cheetham, A.K. The Structures of Some Titanium-Niobium Oxides by Powder Neutron Diffraction. Proc. Royal Soc. A 1974, 338, 311-326. [CrossRef]

19. Hase, M.; Koide, N.; Manabe, K.; Sasago, Y.; Uchinokura, K.; Sawa, A. Antiferromagnetic Long-Range Order caused by Nonmagnetic Impurities; Magnetization of Single-Crystal $\mathrm{Cu}_{1-x} \mathrm{Zn}_{x} \mathrm{GeO}_{3}$. Physica B 1995, 215, 164-170. [CrossRef]

20. Van Smaalen, S.; Daniels, P.; Palatinus, L.; Kremer, R.K. Orthorhombic versus monoclinic symmetry of the charge-ordered state of $\mathrm{NaV}_{2} \mathrm{O}_{5}$. Phys. Rev. B 2002, 65, 060101. [CrossRef]

21. Isobe, M.; Ueda, Y. Effect of Na-deficiency on the spin-Peierls transition in $\alpha^{\prime}-\mathrm{NaV}_{2} \mathrm{O}_{5}$. J. Alloys Compd. 1997, 262-263, 180-184. [CrossRef]

22. Wu, X.; Miao, J.; Han, W.; Hu, Y.-S.; Chen, D.; Lee, J.-S.; Kim, J.; Chen, L. Investigation on $\mathrm{Ti}_{2} \mathrm{Nb}_{10} \mathrm{O}_{29} \mathrm{Anode}$ Material for Lithium-ion Batteries. Electrochem. Commun. 2012, 25, 39. [CrossRef]

(C) 2019 by the authors. Licensee MDPI, Basel, Switzerland. This article is an open access article distributed under the terms and conditions of the Creative Commons Attribution (CC BY) license (http://creativecommons.org/licenses/by/4.0/). 